\title{
SISTEM PAKAR PENENTUAN PEMERIKSAAN LABORATORIUM METODE CASE BASE REASONING
}

\author{
Yulita Safitri*, Andik Adi Suryanto*, Asfan Muqtadir*, Fitroh Amaluddin*, Alfian Nurlifa*, \\ Amaludin Arifia*, Dwi Kurnia Basuki** \\ * Teknik Informatika, Universitas PGRI Ronggolawe \\ ** Teknik Informatika, Politeknik Elektronika Negeri Surabaya \\ Correspondence Author : andikadisuryanto@unirow.ac.id
}

\begin{tabular}{|c|c|}
\hline Info Artikel : & ABSTRACT \\
\hline \multirow[t]{2}{*}{$\begin{array}{l}\text { Sejarah Artikel : } \\
\text { Menerima : } \\
\text { 16 Jan } 2020 \\
\text { Revisi : } \\
\text { 29 Jan } 2020 \\
\text { Diterima : } \\
\text { 02 Febr } 2020 \\
\text { Online : } \\
\text { 04 Febr } 2020 \\
\text { Keyword : } \\
\text { Expert System, } \\
\text { Laboratory } \\
\text { Examination, } \\
\text { Case Base } \\
\text { Reasoning. }\end{array}$} & $\begin{array}{l}\text { Ths study yo design an expert system of determination of labotatory } \\
\text { examination using Case Based Reasoning Method. Kinds of diseases with } \\
\text { similar complaints make it difficult to diagnose a person's illness. Various } \\
\text { laboratory examinations require a pyhsiscian Or laboratory personel to sort } \\
\text { out the checks that should be undertaken. These problems encourage authors } \\
\text { to create systems that can overcome them. This system uses the method of Case } \\
\text { Base Reasoning, the solution obtained is based on cases pf past that have been } \\
\text { completed by the expert. The conlusion of this research is got suggestion of } \\
\text { laboratory examination which is lived based on the complaint or symptom that } \\
\text { is felt and valui of resemblance with previous case.. }\end{array}$ \\
\hline & INTISARI \\
\hline $\begin{array}{l}\text { Kata Kunci : } \\
\text { Expert System, } \\
\text { Laboratory } \\
\text { Examination, } \\
\text { Case Base } \\
\text { Reasoning. }\end{array}$ & $\begin{array}{l}\text { Penelitian ini bertjuan untuk menrancang sistem pakar penentuan } \\
\text { pemeriksaan laboratorium menggunakan Case Based Reasoning. Macam- } \\
\text { macam penyakit dengan keluhan yang hamper sama menyebabkan sulitnya } \\
\text { mendiagnosa penyakit seseorang, sehingga periksaan laboratorium yang } \\
\text { beragam menuntut seoarang dokter atau petugas lanoratorium untuk memiliah } \\
\text { pemeriksaaan yang seharusnya dijalani. Permasalahan tersebut mendorong } \\
\text { peneliti untuk membuat system yang dapat mengatasai permasalahn tersebut. } \\
\text { Sistem ini menggunakan metode Case Based Reasoning yaitu solusi yang } \\
\text { didapatkan didasarkan pada kasus-kasus masa lampau yang telah } \\
\text { diselesaikan oleh ahli atau pakar. Kesimpulan dari penelitian ini yaitu } \\
\text { didapatkan saran pemeriksaan laboratorium yang dijalani berdasarkan } \\
\text { keluhan atau gejala yang dirasakan serta nilai kemiripan dengan kasus } \\
\text { sebelumnya. }\end{array}$ \\
\hline
\end{tabular}




\section{PENDAHULUAN}

Pemeriksaan laboratorium merupakan suatu tindakan dan prosedur untuk pemeriksaan khusuh. Pemeriksaan khusus dengan mengambil dan sampel dari pasien bertujuan untuk menentukan dan membatu diagnosis penyakit dari pasien.

Case Based Reasoning salah satu metode yang digunakan untuk memecahkan permasalahan baru. Dalam memecahkan permasalah Case Based Reasoning menggunakan kasus sebelumnya yang hampir sama dengan masalah baru sehingga menghasilkan pemecahan masalah, pemahaman dan pembelajaran terhadap suatu permasalahan (Aamodt dan Plaza, 1994).

Dalam pemeriksaan atau diagnose penyakit pasien memiliki keluhan yang hampir sama menyebabkan sulitnya mendiagnosa penyakit seorang pasien. Sehingga pemeriksaan laboratorium merupakan jalan utama untuk memecahkan masalah tersebut. Pemeriksaan laboratorium yang beragam menuntut seorang dokter atau petugas laboratorium untuk memilah pemeriksaan yang harus dijalani pasien.

Berdasarkan permasalah tersebut peneliti menggunakan metode Case Based Reasoning untuk membuat sistem yang dapat mengatasi permasalah tersebut dengan didasarkan pada kasuskasus masa lampau yang telah diselesaikan oleh ahli atau pakar.

\section{LANDASAN TEORI}

\subsection{Pemeriksaan Laboratorium}

Pemeriksaan laboratorium ialah suatu tindakan dan prosedur pemeriksaan khusus dengan mengambil bahan atau sampel dari pasien dalam bentuk darah, sputum, urine, kerokan kulit, dan cairan tubuh lainnya dengan tujuan untuk menentukan diagnosis atau membantu menegakkan diagnosis penyakit. Pemeriksaan laboratorium tidak hanya dilakukan bagi individu yang sakit. Individu sehat yang rutin melakukan pemeriksaan laboratorium akan memperoleh banyak manfaat. Pemeriksaan laboratorium dapat berupa Medical Check Up berkala sehingga individu dapat memantau terus kesehatannya. Melakukan Medical Check Up secara rutin hampir tidak ada ruginya.

\subsection{Sistem Pakar}

Sistem pakar (expert system) adalah sistem yang berusaha mengadopsi pengetahuan manusia ke komputer, agar komputer dapat menyelesaikan masalah seperti yang biasa dilakukan oleh para ahli, dan sistem pakar yang baik dirancang agar dapat menyelesaikan suatu permasalahan tertentu dengan meniru kerja dari para ahli (Kusumadewi, 2003).

Sistem pakar merupakan paket perangkat lunak atau paket program komputer yang ditujukan sebagai penyedia nasihat dan sarana bantu dalam memecahkan masalah di bidang-bidang spesialisasi tertentu seperti sains, perekayasaan, matematika, kedokteran, pendidikan dan sebagainya. Sistem pakar merupakan merupakan subset dari Artificial Intelegence (Arhami, 2005).

Sistem pakar adalah suatu sistem komputer yang bisa menyamai atau meniru kemampuan seorang pakar. Pakar yang dimaksud disini adalah orang yang mempunyai keahlian khusus yang dapat menyelesaikan masalah yang tidak dapat diselesaikan orang awam. Contohnya dokter, mekanik, psikolog, dan lain-lain.

\subsection{Case Based Reasoning}

Case Based Reasoning (CBR) berarti menggunakan pengalaman sebelumnya dalam kasus yang mirip untuk memahami dan memecahkan permasalahan baru. Case Based Reasoning (CBR) mengumpulkan kasus sebelumnya yang hampir sama dengan masalah yang baru dan berusaha untuk memodifikasi solusi agar sesuai dengan kasus yang baru (Aamodt dan Plaza, 1994). Case Based Reasoning (CBR) suatu model penalaran yang menggabungkan pemecahan masalah, pemahaman dan pembelajaran serta memadukan keseluhannya dengan pemrosesan memori.

Jika ada sebuah kasus baru, kasus tersebut akan diselesaikan dengan mencari kasus-kasus yang tersimpan dalam basis kasus yang memiliki kemiripan dengan kasus baru tersebut. Apabila tidak ditemukan kemiripan dari kasus yang lama maka solusi dari kasus adalah analisa dari pakar 
atau ahli tentang kasus tersebut, yang kemudian kasus tersebut akan disimpan menjadi kasus baru atau yang disebut dengan retain.

Perhitungan bobot kemiripan (Similitary)

$$
\text { similarity (problem, case) }=\frac{\left(s_{1} * w_{1}\right)+\left(s_{2} * w_{2}\right)+\cdots+\left(s_{n} * w_{n}\right)}{w_{1}+w_{3}+\cdots+w_{n}}
$$

Keterangan :

$\mathrm{S}=$ similarity (nilai kemiripan)

$\mathrm{W}=$ weight (bobot yang diberikan)

Metode Case Based Reasoning merupakan metode yang menerapkan 4 tahapan dalam prosesnya, yaitu retrieve, reuse, revise, dan retrain. Cara kerja metode tersebut berpedoman pada basis pengetahuan yang dimiliki oleh sistem yang bersumber dari kasus - kasus yang pernah ada sebelumnya kemudian dihitung tingkat kemiripannya dengan kasus baru dengan keluhan yang diinputkan oleh pengguna. Berdasarkan kemiripan kasus ini sistem akan mengeluarkan saran pemeriksaan laboratorium yang harus dijalani oleh pengguna.

\section{METODE PENELITIAN}

Adapun Metode penelitian dalam perancangan sistem penentuan pemeriksaan laboratorium metode Case Base Reasoning adalah sebagai berikut :

a. Studi pustaka

Tahapan ini, penulis mengumpulkan teori - teori yang berhubungan dengan perancangan sistem penentuan pemeriksaan laboratorium. Teori - teori tersebut dikumpulkan dari beberapa sumber seperti buku perpustakaan, jurnal teknik informatika, artikel - artikel di internet serta referensi dari tugas akhir mahasiswa yang bertemakan sistem pakar dengan menggunakan metode CBR

b. Mengumpulkan data - data

Pengumpulan data - data adalah langkah penelitian selanjutnya, pada tahap ini peneliti mencari data - data yang dibutuhkan dalam pembangunan sistem. Data yang dibutuhkan beserta sumbernya telah dijelaskan sebelumnya.

c. Merancang program / aplikasi

Pada tahapan ini penulis melakukan perancangan sebuah aplikasi web. Langkah pertama dalam perancangan program ini adalah merancang proses kerja sistem menggunakan bagan alir data DFD yang menjelaskan secara rinci proses - proses yang akan dilakukan program dalam menghasilkan sebuah saran pemeriksaan laboratorium yang tepat.

d. Mengimplementasikan perancangan program / aplikasi

Tahapan ini penulis mengimplementasikan rancangan tampilan program serta melakukan coding sesuai dengan bahasa pemrograman yang digunakan. Tahapan implementasi program ini penulis membuat tampilan form, membuat module - module yang dibutuhkan serta membuat sintak - sintak terhadap link pada halaman web.

e. Melakukan pengujian program (Testing)

Tahapan yang terakhir adalah melakukan pengujian atau testing program dalam hal ini penulis melakukan serangkaian tes terhadap program yang telah dibuat. Tes program bertujuan untuk mendapatkan kesalahan - kesalahan (Trouble) sehingga kesalahan dapat segara diperbaiki sebelum program dinyatakan selesai.

\section{HASIL DAN ANALISA}

\subsection{Pembahasan}

\subsubsection{Data Yang dibutuhkan}

Pembangunan sistem pakar penentuan pemeriksaan laboratorium membutuhkan data sebagai berikut : 
1. Data keluhan umum penderita

Keluhan umum merupakan gejala - gejala yang dirasakan oleh penderita tanpa disertai sebuah indikasi penyakit lain maupun kondisi lain.

2. Data pemeriksaan laboratorium yang termasuk sebagai pemeriksaan awal (screening).

Banyak sekali macam dari pemeriksaan laboratorium, oleh karenanya sebagai dasar dalam pembangunan sistem penulis mengambil beberapa pemeriksaan laboratorium yang merupakan pemeriksaan awal (screening), seperti yang dijelaskan pada tabel 3.1 dibawah ini :

Tabel 1 Panel Utama Pemeriksaan Laboratorium (Herawati, 2018)

$$
\text { Panel Laboratorium }
$$

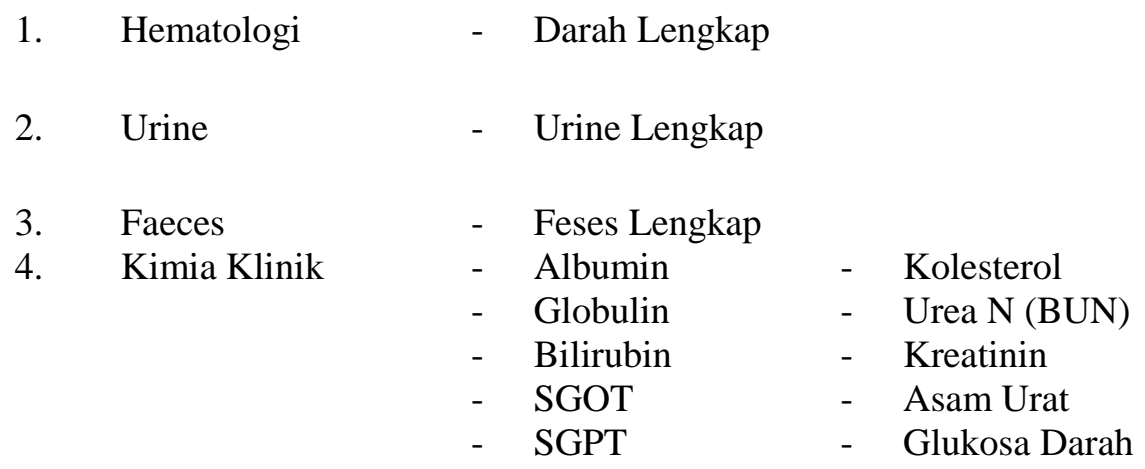

5. Imuno Serologi $\quad-\quad \mathrm{Hbs} \mathrm{Ag}$

- $\quad$ IgG / IgM Anti Dengue

- Ns1 Dengue

- Widal

$\begin{array}{llll}\text { 6. } & \text { Jantung } & - & \text { Electro Cardiografi } \\ \text { 7. } & \text { Microbiologi } & - & \text { Malaria } \\ & & - & \text { BTA } \\ \text { 8. } & \text { USG } & & \\ & & - & \text { Upper \& Lower Abdomen } \\ \text { 9. } & \text { X-Ray } & - & \text { Thorax PA } \\ & & - & \text { BOF }\end{array}$

3. Data bobot pemeriksaan terhadap berbagai keluhan yang ada.

Bobot pemeriksaan digunakan sebagai dasar dari perhitungan nilai kemiripan kasus baru terhadap kasus yang telah ada. Pemberian bobot pemeriksaan terhadap keluhan dijabarkan pada tabel 3.2 dibawah ini : 
Tabel 2 Bobot nilai kepentingan (Herawati, 2018)

\begin{tabular}{|c|c|c|}
\hline Pemeriksaan & Keluhan & Bobot \\
\hline Darah Lengkap & $\begin{array}{ll}- & \text { Demam } \\
- & \text { Pusing } \\
- & \text { Lemas }\end{array}$ & $\begin{array}{l}5 \\
5 \\
3\end{array}$ \\
\hline Urine Lengkap & $\begin{array}{ll}- & \text { Demam } \\
- & \text { Sakit perut } \\
- & \text { Nyeri kencing } \\
\text { - } & \text { Sering kecing } \\
\text { - } & \text { Urine warna merah } \\
- & \text { Urine disertai darah } \\
- & \text { Urine keruh } \\
- & \text { Muka bengkak }\end{array}$ & $\begin{array}{l}3 \\
3 \\
5 \\
5 \\
5 \\
5 \\
5 \\
1\end{array}$ \\
\hline Feses Lengkap & $\begin{array}{c}-\quad \text { Pusing } \\
-\quad \text { Pucat } \\
-\quad \text { Feses berdarah, lendir, cair }\end{array}$ & $\begin{array}{l}1 \\
3 \\
5\end{array}$ \\
\hline SGOT / SGPT & $\begin{array}{c}-\quad \text { Badan kuning (mata, kuku) } \\
-\quad \text { Pusing } \\
-\quad \text { Mual } \\
-\quad \text { Perut membesar }\end{array}$ & $\begin{array}{l}5 \\
3 \\
3 \\
5\end{array}$ \\
\hline BUN / Kreatinin & $\begin{array}{c}-\quad \text { Mual } \\
-\quad \text { Nyeri daerah perut - punggung } \\
-\quad \text { Pusing } \\
-\quad \text { Urine keruh }\end{array}$ & $\begin{array}{l}3 \\
5 \\
3 \\
1\end{array}$ \\
\hline Kolesterol Lengkap & 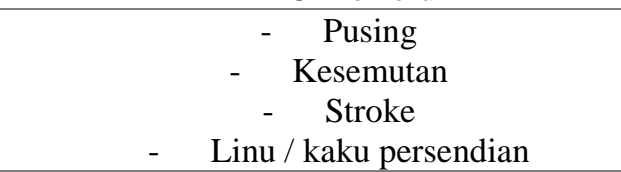 & $\begin{array}{l}5 \\
3 \\
5 \\
5\end{array}$ \\
\hline Malaria & $\begin{array}{c}-\quad \text { Demam } \\
-\quad \text { Riwayat tempat tinggal (luar jawa) } \\
-\quad \text { Pusing }\end{array}$ & $\begin{array}{l}3 \\
5 \\
1\end{array}$ \\
\hline Asam Urat & $\begin{array}{c}-\quad \text { Kesemutan } \\
\text { - Linu / kaku persendian }\end{array}$ & $\begin{array}{l}3 \\
5\end{array}$ \\
\hline Glukosa Darah & $\begin{array}{ccc}- & \text { Berat Badan menurun drastis } \\
& -\quad \text { Mudah mengantuk } \\
- & \text { Sering kencing malam } \\
-\quad \text { Luka tidak sembuh }- \text { sembuh } \\
-\quad \text { Pandangan kabur } \\
& -\quad \text { Mudah lelah }\end{array}$ & $\begin{array}{l}3 \\
3 \\
5 \\
5 \\
3 \\
3\end{array}$ \\
\hline
\end{tabular}

Bobot Parameter (w) :

Keluhan Penting : : 5

Keluhan Sedang $\quad: 3$

Keluhan Biasa $\quad: 1$

\subsubsection{Perancangan Sistem}

\subsubsection{Flowchart Sistem Pakar}

Sebuah sistem memiliki alur kerja atau alur proses yang terdapat didalamnya sehingga dapat berjalan sesuai dengan kebutuhan. Adapun alur sistem dapat dilihat pada gambar 1 


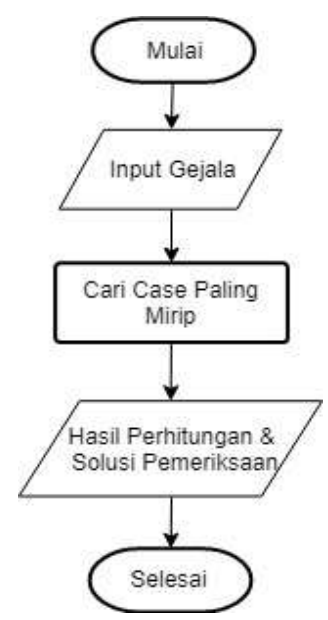

Gambar 1 Flowchart Sistem

Pada flowchart gambar 1 menjelaskan tentang bagaimana alur dari user untuk bisa mendapatkan solusi pemeriksaan dari gejala yang diinputkan.

\section{Flowchart Case Base Reasoning}

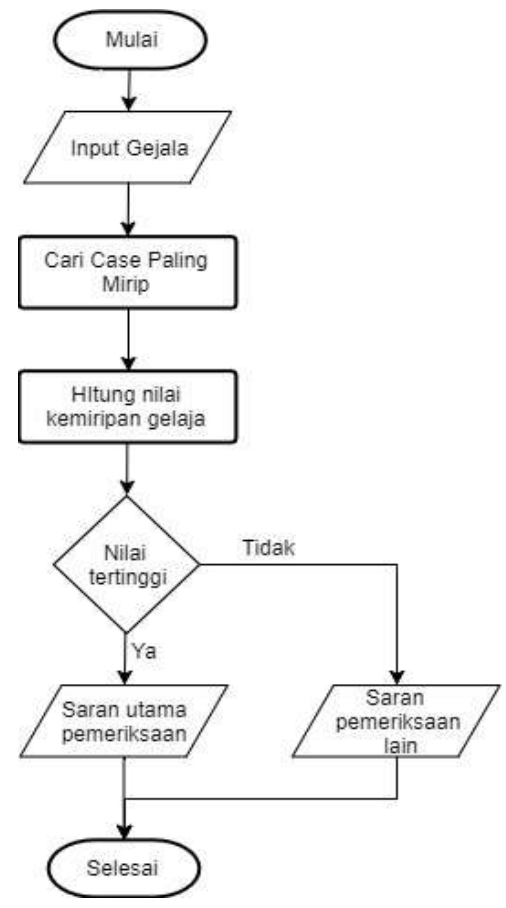

Gambar 2 Flowchart CBR

Gambar 2 merupakan flowchart dari Case Base Reasoning yang menjelaskan alur suatu kasus baru yang diinput oleh user. Input gejala dari user akan diproses dengan menggunakan metode Case Based Reasoning sehingga menghasilkan rekomendasi pemeriksan laboratorium .

\subsubsection{Context Diagram}

Data Flow Diagram digunakan untuk menggambarkan keseluruhan dari sistem yang dirancang. Adapun perancangannya dapat dilihat pada gambar 3 berikut : 


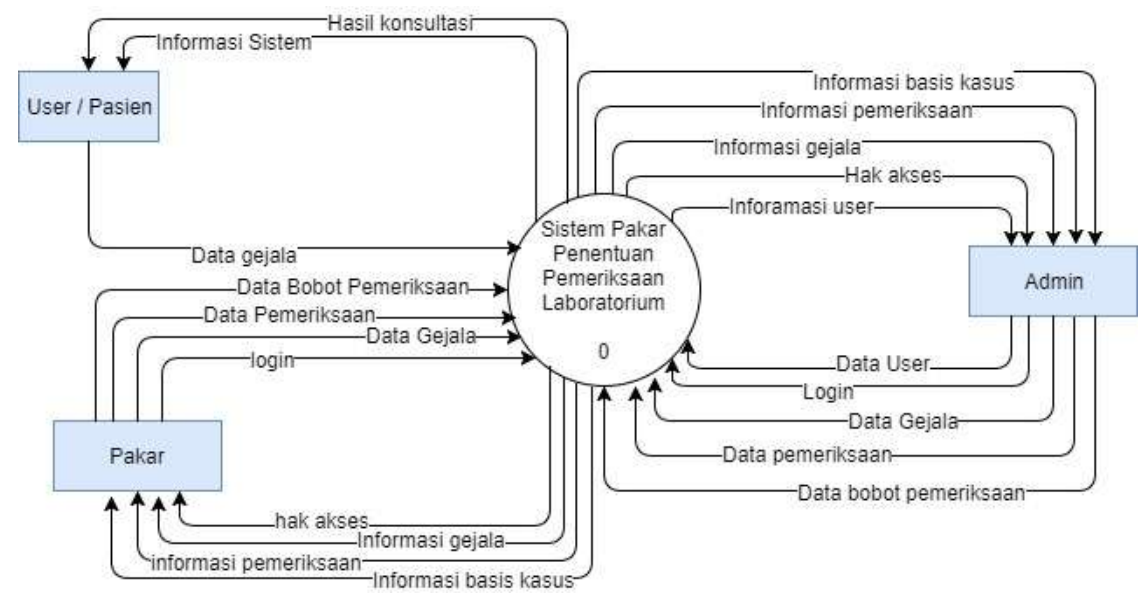

Gambar 3 Context Diagram

Keterangan :

1. Sistem yang dibangun memiliki 3 entitas eksternal, yaitu user / pasien / pengguna, Admin dan Pakar

2. User dapat melakukan input gejala untuk memperoleh hasil konsultasi dari sistem.

3. User dapat melihat informasi mengenai sistem tanpa bisa mengelola data sistem

4. Admin memiliki akses penuh terhadap sistem untuk pengelolaan data seperti menambah, menghapus serta merubah data pada sistem, termasuk data user sehingga Admin dapat melihat semua informasi pada sistem

5. Pakar memiliki akses terhadap data gejala, pemeriksaan dan bobot pemeriksaan tapi tidak dengan data user.

\subsection{Hasil}

\subsubsection{Implementasi Interface}

\subsubsection{Halaman Utama}

Halaman pembuka pada sitem pakar penentuan pemeriksaan laboratorium berisikan sedikit informasi tentang metode yang dipakai. Halaman ini diperuntukan bagi user yang akan menggunakan sistem. Tampilan halaman utama dapat dilihat pada gambar 4 berikut :

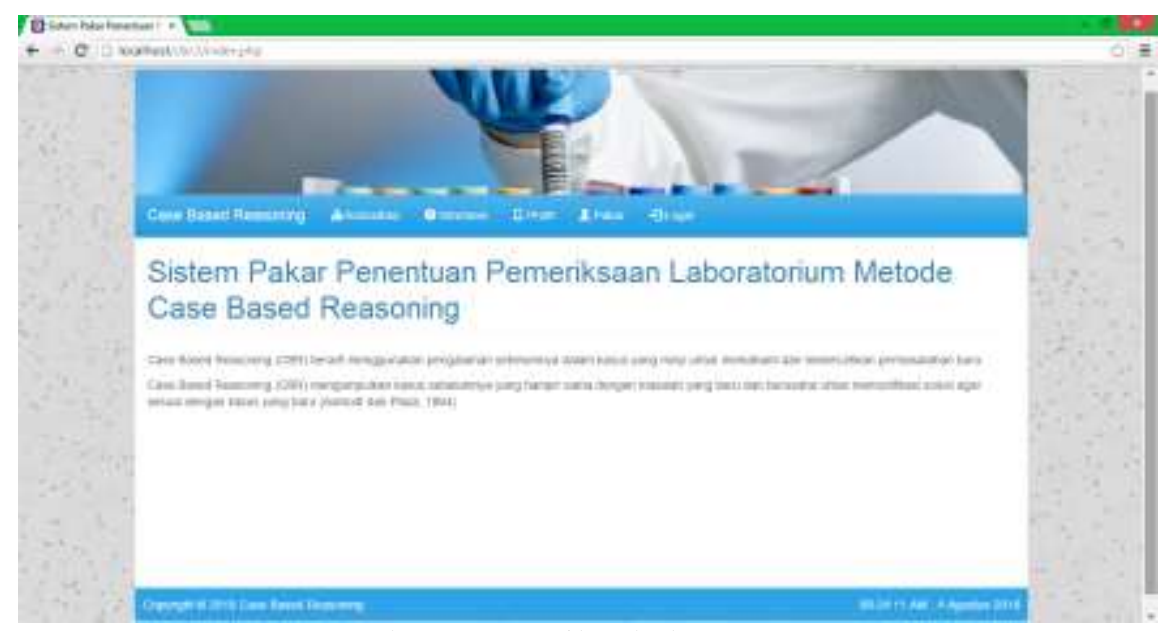

Gambar 4 Tampilan halaman utama

\subsubsection{Halaman Konsultasi}

Halaman konsultasi pada gambar 5 dapat digunakan oleh siapapun, termasuk admin, pakar, dan user yang bersifat umum. Halaman konsultasi digunakan oleh user untuk memasukkan gejala 
yang dialami. Pada halaman konsultasi terdapat 43 pertanyaan yang perlu dijawab, perhalaman berisi 10 pertanyaan. Sebelum masuk pada halaman konsultasi pengguna diharuskan untuk mengisi tanggal lahir karena sistem memiliki batasan usia untuk mengaksesnya.

Tampilan halaman konsultasi dan verifikasi usia dapat dilihat pada gambar 5, 6 dan 7 sebagai berikut:
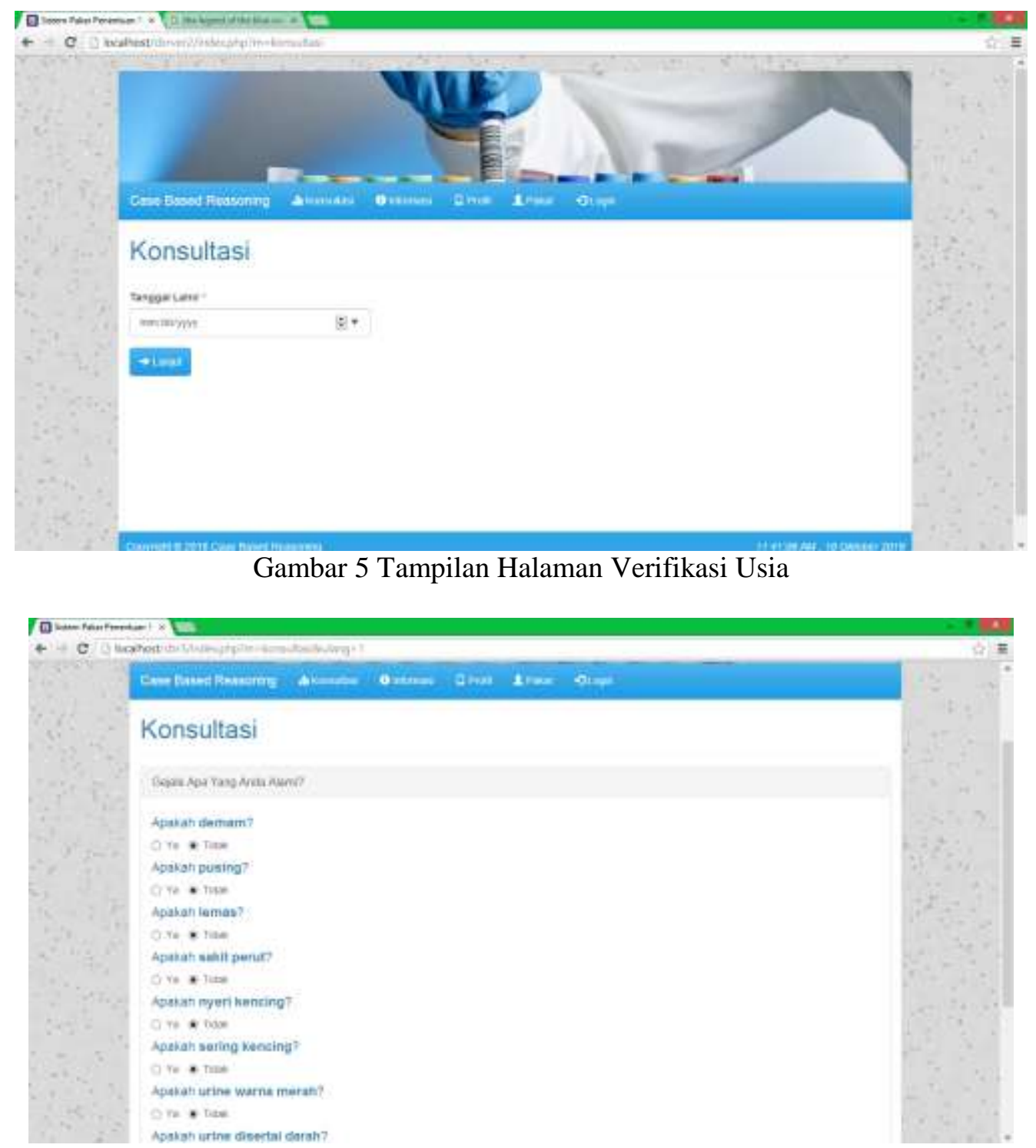

Gambar 6 Halaman Konsultasi

Setelah memilih gelaja dan dirasa cukup, maka untuk memperoleh saran pemeriksaan dari gejala yang diinputkan user harus menekan tombol berikutnya atau lihat hasil untuk mengetahui hasil konsultasi.Seperti yang terlihat pada gambar 7.

\subsubsection{Halaman Hasil Konsultasi}

Pada gambar 8 merupakan Halaman hasil konsultasi ditampilkan otomatis setelah user menekan tombol lihat hasil pada halaman konsultasi. Halaman hasil konsultasi menampilkan gejala yang terpilih oleh user, perhitungan dan saran pemeriksaan. Tampilan halaman hasil konsultasi dapat dilihat pada gambar 8 berikut : 


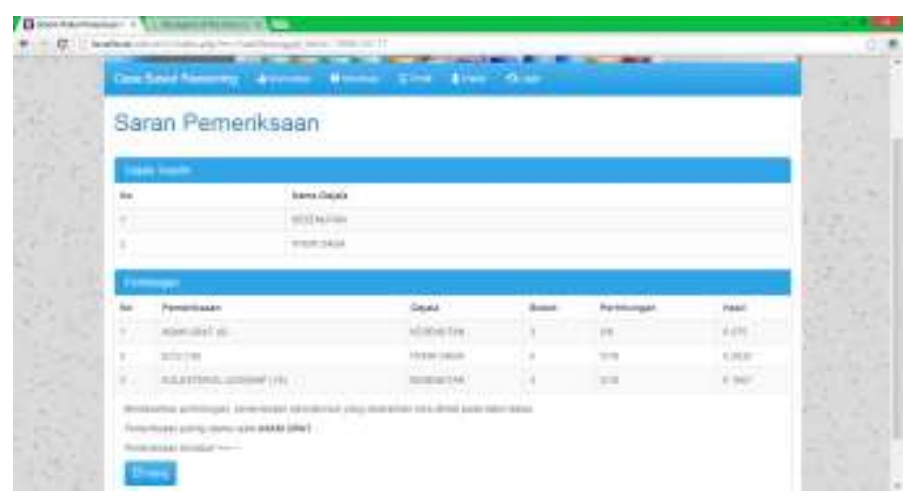

Gambar 8Tampilan halaman hasil konsultasi

\subsubsection{Analisa Perhitungan Sistem}

Gejala yang terpilih :

1. Pusing

2. Kesemutan

3. Linu \& kaku persendian

4. Mudah lelah

Hasil Pencarian Kemiripan dapat dilihat pada tabel 3 dibawah ini :

Tabel 3 Hasil Pencarian Kemiripan

\begin{tabular}{|c|c|c|}
\hline Kasus Lama & Pemeriksaan & Gejala \\
\hline 1. & Darah Lengkap & $\begin{array}{ll}- & \text { Demam } \\
- & \text { Pusing } \\
- & \text { Lemas }\end{array}$ \\
\hline 2. & Feses Lengkap & $\begin{array}{ll}- & \text { Pusing } \\
- & \text { Pucat } \\
- & \text { Feses berdarah, lendir, cair }\end{array}$ \\
\hline 3. & SGOT / SGPT & $\begin{array}{ll}- & \text { Badan kuning (mata, kuku) } \\
- & \text { Pusing } \\
- & \text { Mual } \\
- & \text { Perut membesar }\end{array}$ \\
\hline 4. & BUN / Kreatinin & $\begin{array}{ll}- & \text { Mual } \\
- & \text { Nyeri daerah perut - punggung } \\
- & \text { Pusing } \\
- & \text { Urine keruh }\end{array}$ \\
\hline 5. & Kolesterol Lengkap & $\begin{array}{ll}- & \text { Pusing } \\
- & \text { Kesemutan } \\
- & \text { Stroke } \\
- & \text { Linu / kaku persendian } \\
\end{array}$ \\
\hline 6. & Malaria & $\begin{array}{ll}- & \text { Demam } \\
- & \text { Riwayat tempat tinggal (luar jawa) } \\
- & \text { Pusing }\end{array}$ \\
\hline 7. & Asam Urat & $\begin{array}{ll}- & \text { Kesemutan } \\
- & \text { Linu / kaku persendian }\end{array}$ \\
\hline 8. & Glukosa Darah & $\begin{array}{ll}\text { - } & \text { Berat Badan menurun drastis } \\
\text { - } & \text { Mudah mengantuk } \\
\text { - } & \text { Sering kencing malam } \\
\text { - } & \text { Luka tidak sembuh - sembuh } \\
\text { - } & \text { Pandangan kabur } \\
\text { - } & \text { Mudah lelah }\end{array}$ \\
\hline
\end{tabular}


Perhitungan ini mengambil beberapa kasus yang cocok dengan gejala terpilih pada contoh kasus diatas. Proses pembobotan yang dilakukan oleh sistem ditampilkan dalam perhitungan dibawah ini :

1. Darah Lengkap

\begin{tabular}{|c|c|c|c|}
\hline & KASUS LAMA & BOBOT & KASUS BARU \\
\hline 5 & DEMAM & 0 & \\
\hline 5 & PUSING & 1 & PUSING \\
\hline 3 & LEMAS & 0 & $\begin{array}{l}\text { LINU / KAKU } \\
\text { PERSENDIAN }\end{array}$ \\
\hline 13 & & & MUDAH LELAH \\
\hline & & & KESEMUTAN \\
\hline
\end{tabular}

2. Feses Lengkap

\begin{tabular}{clcl}
\hline & KASUS LAMA & BOBOT & KASUS BARU \\
\hline $\mathbf{1}$ & PUSING & 1 & PUSING \\
\hline $\mathbf{3}$ & PUCAT & 0 & $\begin{array}{l}\text { LINU / KAKU } \\
\text { PERSENDIAN }\end{array}$ \\
\hline $\mathbf{5}$ & $\begin{array}{l}\text { FESES DARAH, LENDIR, } \\
\text { CAIR }\end{array}$ & 0 & MUDAH LELAH \\
\hline $\mathbf{9}$ & \multicolumn{2}{c}{ KESEMUTAN } \\
\hline & & $S=\frac{(1 * 1)+(3 * 0)+(5 * 0)}{1+3+5}=0,111$
\end{tabular}

3. SGOT/SGPT

\begin{tabular}{clcl}
\hline & KASUS LAMA & BOBOT & KASUS BARU \\
\hline $\mathbf{5}$ & $\begin{array}{l}\text { BADAN KUNING (MATA, } \\
\text { KUKU) }\end{array}$ & 0 & \\
\hline $\mathbf{3}$ & PUSING & 1 & PUSING \\
\hline $\mathbf{3}$ & MUAL & 0 & $\begin{array}{l}\text { LINU / KAKU } \\
\text { PERSENDIAN }\end{array}$ \\
\hline $\mathbf{5}$ & PERUT MEMBESAR & 0 & MUDAH LELAH \\
\hline $\mathbf{1 6}$ & & & KESEMUTAN \\
\hline
\end{tabular}

$$
S=\frac{(0 * 5)+(1 * 3)+(0 * 3)+(0 * 5)}{5+3+3+5}=0,1875
$$

4. Bun Kreatinin

\begin{tabular}{llcl}
\hline & KASUS LAMA & BOBOT & KASUS BARU \\
\hline $\mathbf{3}$ & MUAL & 0 & \\
\hline $\mathbf{5}$ & $\begin{array}{l}\text { NYERI DAERAH PERUT }- \\
\text { PUNGGUNG }\end{array}$ & 0 & \\
\hline $\mathbf{3}$ & PUSING & 1 & PUSING \\
\hline $\mathbf{1}$ & URINE KERUH & 0 & $\begin{array}{l}\text { LINU / KAKU } \\
\text { PERSENDIAN }\end{array}$ \\
\hline $\mathbf{1 2}$ & & & MUDAH LELAH \\
\hline & & & KESEMUTAN \\
\end{tabular}




$$
S=\frac{(0 * 3)+(0 * 5)+(1 * 3)+(0 * 1)}{3+5+3+1}=0,25
$$

5. Kolesterol Lengkap

\section{KASUS LAMA}

\begin{tabular}{clrl}
\hline $\mathbf{5}$ & PUSING & 1 & PUSING \\
\hline $\mathbf{5}$ & LINU / KAKU PERSENDIAN & 1 & $\begin{array}{l}\text { LINU / KAKU } \\
\text { PERSENDIA }\end{array}$ \\
$\mathbf{5}$ & STROKE & 0 & MUDAH LELA \\
\hline $\mathbf{3}$ & KESEMUTAN & 1 & KESEMUTAN \\
\hline $\mathbf{1 8}$ & & $(1 * 5)+(1 * 5)+(0 * 5)+(1 * 3)$ \\
& & $5=\frac{(1+5+5+3}{}$
\end{tabular}

6. Malaria

\begin{tabular}{clcl}
\hline & KASUS LAMA & BOBOT & KASUS BARU \\
\hline $\mathbf{1}$ & PUSING & 1 & PUSING \\
\hline $\mathbf{3}$ & DEMAM & 0 & $\begin{array}{l}\text { LINU / KAKU } \\
\text { PERSENDIAN }\end{array}$ \\
\hline $\mathbf{5}$ & $\begin{array}{l}\text { RIWAYAT TEMPAT TINGGAL } \\
\text { (LUAR JAWA) }\end{array}$ & 0 & MUDAH LELAH \\
\hline $\mathbf{9}$ & \multicolumn{2}{c}{\begin{tabular}{l} 
KESEMUTAN \\
\hline
\end{tabular}} & \multicolumn{1}{c}{$S=\frac{(1 * 1)+(0 * 3)+(0 * 5)}{1+3+5}=0,11$}
\end{tabular}

7. Asam Urat

\begin{tabular}{llcl}
\hline & KASUS LAMA & BOBOT & KASUS BARU \\
\hline $\mathbf{3}$ & KESEMUTAN & 1 & KESEMUTAN \\
\hline $\mathbf{5}$ & LINU / KAKU PERSENDIAN & 1 & LINU / KAKU \\
& & PERSENDIAN \\
\hline $\mathbf{8}$ & & MUDAH LELAH \\
\hline & & PUSING \\
\hline & & \\
& & &
\end{tabular}

8. Glukoasa Darah

\begin{tabular}{clcl}
\hline & KASUS LAMA & BOBOT & KASUS BARU \\
\hline $\mathbf{3}$ & BERAT BADAN MENURUN & 0 & \\
& DRATIS & & \\
\hline $\mathbf{3}$ & MUDAH NGANTUK & 0 & \\
\hline $\mathbf{5}$ & SERING KENCING MALAM & 0 & KESEMUTAN \\
\hline $\mathbf{5}$ & LUKA TIDAK SEMBUH - SEMBUH & 0 & LINU / KAKU \\
& & 0 & PERSENDIAN \\
\hline $\mathbf{3}$ & PANDANGAN KABUR & 1 & MUDAH LELAH \\
\hline $\mathbf{3}$ & MUDAH LELAH & \\
\hline $\mathbf{2 2}$ & \multicolumn{3}{c}{$S=\frac{(0 * 3)+(0 * 3)+(0 * 5)+(0 * 5)+(0 * 3)+(1 * 3)}{3+3+5+5+3+3}$} \\
\hline
\end{tabular}


Dari perhitungan diatas didapatkan adalah saran pemeriksaan yang memiliki nilai bobot kemiripan antara kasus baru dengan kasus lama yang paling tinggi, dalam contoh kasus ini adalah pemeriksaan Asam Urat. Sehingga pada kasus baru yang digejalanya telah diinputkan diatas saran pemeriksaan yang terbaik ialah Asam Urat, kemudian saran pemeriksaan lain yang memiliki nilai tertinggi sehingga dapat dijadikan pertimbangan.

\section{KESIMPULAN}

Berdasarkan penelitian dan perancangan pada sistem pakar penentuan pemeriksaan laboratorium maka dapat disimpulkan beberapa hal antara lain sebagai berikut :

1. Sistem pakar ini mengolah data pemeriksaan dengan gejala - gejala yang termuat dalam batasan masalah dan dioleh oleh admin yang telah mempunyai akun pada sistem

2. Sistem dapat memberikan hasil konsultasi dan perhitungan nilai kemiripan terhadap kasus masa lampu serta saran pemeriksaan laboratorium. 


\section{DAFTAR PUSTAKA}

Aamodt, A., dan Plaza, E., 1994. Case Based Reasoning : Foundational Issues, Methodological Varations. And System Approaches. AI Communications, $7: 39$ - 59.

Akmal, Faza dan Sri Winarti. 2014. Sistem Pakar Untuk Mendiagnosa Penyakit Lambung Dengan Implementasi Metode CBR (Case-Based Reasoning) Berbasis Web. Jurnal Sarjana Teknik Informatika. 2(1) : $790-800$.

Arhami, Muhammad. 2005. Konsep Dasar Sistem Pakar. Yogyakarta : Andi Yogyakarta.

Arie, M. Rudianto. 2011. Pemrogaman Web Dinamis menggunakan PHP dan MySQL. Yogyakarta : Andi Offset Yogyakarta

Brady, M., and Loonam, J. 2010. Explosing the use of entity realitionship diagramming as technique to support grounded theory inquiry. Bradford : Emerald Group.

Helper Bali,2017. Pemeriksaan Laboratorium - Definisi, Fungsi dan Persiapan, (http://mhbali.com/definisi-fungsi-pemeriksaan-laboratorium/ diakses tanggal 26 Juni 2018)

Indrajani. 2015. Database Design. Jakarta : PT Elex Media Komputindo.

Kusumadewi, Sri. 2003. Artifical Intelligence (Teknik dan Aplikasinya). Yogyakarta : Graha Ilmu

Lab Populer, 2018. Laboratorium Klinik. (http://lab-populer.com/layanan/lab-klinik/ diakses tanggal 26 Juni 2018)

Lestar D.2012. Definisi sistem pakar. Arsip Jurnal Teknik Informatika UMMI.

Lubis, Adyanata. 2016. Sistem Pakar Konsultasai Penyakit Kehamilan Berbasis Kasus Menggunakan Methode Case Based Reasoning (CBR). Riau Journal Pf Computer Science. 2(1): $66-75$.

Octaviani, S. Fransisca,dkk. 2007. 2007. Implementasi Case Based Reasoning Untuk Sistem Diagonosis Penyakit Anjing. Jurnal Teknik Informatika.

Samsudin, Usman, Selviana. 2017. Aplikasi Sistem Pakar Diagnosa Penyakit Pernapasan Menggunakan Metode Case Based Reasoning. Jurnal IPTEKS Terapan Research of Applied Science and Education. 7(i3) : $272-282$.

Sukamto, R. A., dan Shalahudin, M. 2014. Rekayasa Perangkat Lunak Terstruktur dan Berorientasi Objek. Bandung : Informatika Bandung.

Turban, E., 1995. Decisions Support System dan Expert Syestem. USA : Prentice Hall Internasional Inc. 